\title{
Article \\ Cross-sectional analysis of the resistance of RC members subjected to bending with/without axial force
}

\author{
Marek Lechman ${ }^{1, *}$ \\ 1,* Instytut Techniki Budowlanej, 00-611 Warszawa, ul. Filtrowa 1, Poland; m.lechman@itb.pl; Tel.: +48 225796 117;
}

\begin{abstract}
The paper presents section models for analysis of the resistance of RC members subjected to bending moment with or without axial force. To determine the section resistance the nonlinear stress-strain relationship for concrete in compression is assumed, taking into account the concrete softening. It adequately describes the behavior of RC members up to failure. For the reinforcing steel linear elastic-ideal plastic model is applied. For the ring cross-section subjected to bending with axial force the normalized resistances are derived in the analytical form by integrating the cross-sectional equilibrium equations. They are presented in the form of interaction diagrams and compared with the results obtained by testing conducted on RC columns under eccentric compression. Furthermore, the ultimate normalized bending moment has been derived for the rectangular cross-section subjected to bending without axial force. It was applied in the cross-sectional analysis of steel and concrete composite beams, named $\mathrm{BH}$ beams, consisting of the RC rectangular core placed inside a reversed TT welded profile. The comparisons made indicated good agreements between the proposed section models and experimental results.
\end{abstract}

Keywords: resistance, bending, axial force, reinforced concrete, composite, section models

\section{Introduction}

The resistance of RC members subjected to bending with or without axial force is considered as a theoretical problem as well as a practical one. Such structures and members are frequently encountered in the engineering practice, e.g. columns, TV towers, industrial chimneys, antenna carriers, steel and concrete composite beams. For determining the resistance of cross-sections of the structures like these a variety of physical models of materials and methods are applied. Most often a simplified approach is used based on the rectangular stress distribution in concrete and represented among others by Knauff [1]. Bi-linear stress-strain relation for concrete is also applied. For the design of cross-sections parabola-rectangle diagram for concrete may be also assumed which was introduced by Nieser and Engel [2] in German code as well as in CICIND Model Code for Concrete Chimneys. According to ACI Standard 307-08 parabolic-trapezoidal stress distribution for concrete in compression is used which was proposed by Hognestad [3]. A review of material laws for concrete and the experimental justification of formulae for the estimation of the complete stress-strain diagram of concrete was presented by Popovics [4, 5]. As regards to the reinforcing steel such models are used as: linear elastic, linear elastic-ideal plastic and linear elastic-plastic with hardening. For analysis of the resistance of ring cross-sections deformation models combined with physical nonlinearity of concrete and reinforcing steel were proposed by Lechman [6], based on the above mentioned parabola-rectangle diagram. For determining the resistance of RC cross-sections he also developed an algorithm that takes into account the effect of concrete softening [7,8]. Among structural members subjected to the axial force and bending, reinforced concrete columns are the subject of particular interest of many researchers due to their importance in the engineering practice. The results of FE modeling of failure behavior of RC eccentrically compressed columns were presented by Majewski et al. [9] and Rodrigues et al. [10]. In the study performed by Kim and Lee [11], a numerical method for predicting the behavior of RC columns subjected to axial force and biaxial bending is proposed considering curvature localization combined with verification by a series of tests. A comparison made between the numerical and the test results showed good agreements in ultimate loads and axial force-lateral deflection relation. The presence of the transverse reinforcement changes the failure patterns, improves the nominal strengths and makes the post-critical behavior of columns less brittle. The eccentricity of the applied axial load caused substantial variation in the peak load, ultimate strength and failure modes. The investigations of the load-bearing capacity of RC columns under eccentric compression were conducted by many 
researchers, among others by Lloyd et al. [12], Chruściel [13]. In recent years newly designed floor slab systems are the subject of particular interest of civil engineers and researches. The systems like these consist of steel and concrete composite beams, structurally connected with prefabricated or cast in situ slabs [14, 15]. The results of FEM modeling of failure behavior revealed that significant differences in the ultimate bending moments occur compared to the bending test results. Therefore, the cross-sectional analysis is to be employed. Despite the variety of methods and calculation procedures concerning this problem, there are no appropriate analytical solutions based on the nonlinear material law for determining the section resistance with allowance for the concrete softening. In this contribution a complete analytical solution for ring section resistance is obtained and presented in the form of the actual carrying capacity curves axial force - bending moment, which satisfy the stability conditions by Drucker [16]. Moreover, the ultimate normalized bending moment is derived for the rectangular cross-section subjected to bending without axial force and applied to determining the resistance of steel and concrete composite beams.

In the presented derivation the following assumptions are introduced:

- plane cross-sections remain plane

- elasto-plastic stress-strain relationships for concrete and reinforcing steel are used

- the tensile strength of concrete is ignored

- the ultimate strain for concrete is defined as $\varepsilon_{c u}$, while for reinforcing steel as $\varepsilon_{s u}$.

The resistance of the RC cross-section is reached when either ultimate compressive strain in concrete $\varepsilon_{c u}$ or ultimate tensile strain in steel $\varepsilon_{s u}$ is reached anywhere in that section. On the basis of a combinatorial approach, all possible cases of the stress distribution in concrete and reinforcing steel are considered.

According to Eurocode 2 the stress-strain relation for concrete $\sigma_{c}-\varepsilon_{c}$ in compression for short term uniaxial loading is recommended for non-linear structural analysis as:

$$
\sigma_{c}=\frac{k \eta-\eta^{2}}{1+(k-2) \eta} f_{c m}
$$

where: $\eta=\varepsilon_{c} / \varepsilon_{c 1}, \varepsilon_{c 1}$ - the strain at peak stress on the $\sigma_{c}-\varepsilon_{c}$ diagram, $k=1,05 E_{c m}\left|\varepsilon_{c 1}\right| / f_{c m}, f_{c m}$ - the mean compressive strength of concrete, $E_{c m}$ - secant modulus of elasticity of concrete. This stress-strain relation adequately represents the behavior of concrete by introducing four parameters: $f_{c m}, \varepsilon_{c 1}, \varepsilon_{c u}$ and $E_{c m}$. For reinforcing and profile steels, characterized by yield stresses $f_{y k}, f_{H y k}$, respectively, linear elastic - ideal plastic model is applied.

\section{Ring cross-section subjected to bending with axial force}

\subsection{Derivation of analytical formulae for the resistance}

The RC ring cross-section of the outer radius $R$, the inner radius $r$ and the thickness $t$ is subjected to the axial force $N$ and bending moment $M$ (Fig.1). The section may be unreinforced or reinforced with the reinforcing steel spaced at one or two layers which can be replaced by a continuous ring of equivalent area located on the reference circumference of radius $r_{s}$.

Let us consider the section under combined compression and bending. The geometrical relations for strains in the concrete $\varepsilon_{c}, \%$, and in the reinforcing steel $\varepsilon_{s}, \%$, are expressed by the formulae:

$$
\begin{gathered}
\varepsilon_{c}=(\cos \varphi-\cos \alpha) \varepsilon_{\alpha}^{\prime} \\
\varepsilon_{s}=(\rho \cos \varphi-\cos \alpha) \varepsilon_{\alpha}^{\prime}
\end{gathered}
$$

where $\varphi$ - angular coordinate, $\mathrm{rad}, \alpha$ - angle describing the location of the neutral axis, $\operatorname{rad}, \rho-\operatorname{coefficient}, \rho=r_{\mathrm{s}} / r_{\mathrm{m}}$, $\rho_{\mathrm{R}}$ - coefficient, $\rho_{\mathrm{R}}=R / r_{\mathrm{m}}, \varepsilon^{\prime}-$ the maximum compressive strain in concrete at the point $(0, R), \%$ o, $\varepsilon_{\alpha}^{\prime}=\varepsilon^{\prime} /\left(\rho_{R}-\cos \alpha\right)$, $r_{\mathrm{m}}$ - the mean radius of the ring. All angles are measured from the compressive to the tensile zone. The equilibrium equation of the axial forces in the cross-section takes the following form: 


$$
\int_{A_{c}} \sigma_{c} d A_{c}+\int_{A_{s}} \sigma_{s} d A_{s}+N=0
$$

The sectional equilibrium of the bending moments about the symmetry axis of the section can be expressed in the form:

$$
\int_{A_{c}} \sigma_{c} r_{m} \cos \varphi d A_{c}+\int_{A_{s}} \sigma_{s} r_{s} \cos \varphi d A_{s}-M=0
$$
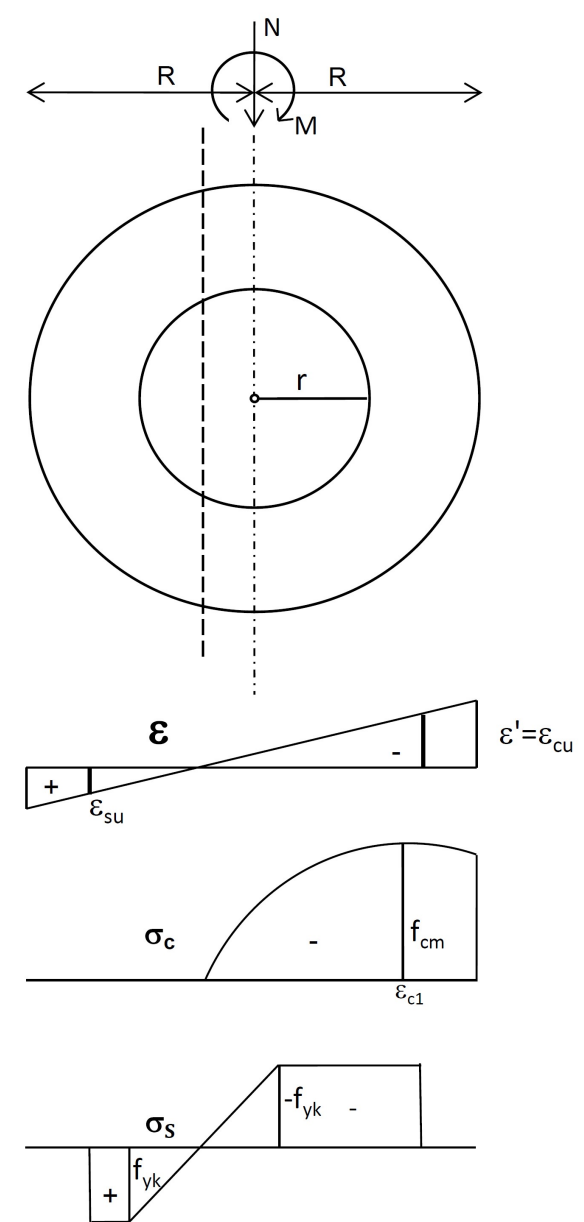

Figure 1. The RC ring cross-section. Distribution of strains $\varepsilon$, stresses in concrete $\sigma_{\mathrm{c}}$ and stresses in reinforcing steel $\sigma_{\mathrm{s}}$ across the section.

The resistance of the RC ring cross-section is reached when one of the following conditions shall be satisfied:

$$
\begin{gathered}
\varepsilon^{\prime}=\varepsilon_{c u} \\
(-\rho-\cos \alpha) \varepsilon_{\alpha}^{\prime}=\varepsilon_{s u}
\end{gathered}
$$

Taking account of the physical and geometrical relationships (1) - (3) in the equilibrium equations (4) and (5), the problem leads to the purely mathematical task consisted in the searching an indefinite integrals of the following functions of variable $\varphi$ : 


$$
\begin{gathered}
f_{N}(\varphi)=\frac{k k_{2}\left(\cos \varphi-k_{1}\right)-k_{2}^{2}\left(\cos \varphi-k_{1}\right)^{2}}{1+(k-2) k_{2}\left(\cos \varphi-k_{1}\right)} \\
f_{M}(\varphi)=\frac{k k_{2}\left(\cos \varphi-k_{1}\right)-k_{2}^{2}\left(\cos \varphi-k_{1}\right)^{2}}{1+(k-2) k_{2}\left(\cos \varphi-k_{1}\right)} \cos \varphi
\end{gathered}
$$

where:

$$
k_{1}=\cos \alpha, \quad k_{2}=\varepsilon_{\alpha}^{\prime} / \varepsilon_{c 1}
$$

On transformation, the functions (8), (9) become:

$$
\begin{gathered}
\left.f_{N}(\varphi)=\left(k_{2} /(k-2)\right)\left[\sin \varphi-\left(k_{1}+W_{2}\right)+2 W_{1} W_{2} \frac{1}{\cos \varphi+b}\right)\right] \\
f_{M}(\varphi)=\left(k_{2} /(k-2)\right)\left[0.5(0.5 \sin 2 \varphi+\varphi)+W_{1} W_{2} \varphi-k_{1} W_{2} \sin \varphi-2 W_{1} W_{2} b /\left(\sqrt{b^{2}-1}\right) \frac{1}{\cos \varphi+b}\right]
\end{gathered}
$$

where: $\quad W_{1}=1 /(k-2) k_{2}, W_{2}=W_{1}+k / k_{2}, b=W_{1}-k_{1}$.

An indefinite integral of the function $1 /(\cos \varphi+b)$ occurring in $(11)-(12)$ has been found as follows:

$$
\begin{array}{cl}
\int \frac{d \varphi}{\cos \varphi+b}=\frac{2}{\sqrt{b^{2}-1}} \operatorname{arctg} \frac{(b-1) \operatorname{tg} 0.5 \varphi}{\sqrt{b^{2}-1}} & \text { for } \quad b^{2}>1 \\
\int \frac{d \varphi}{\cos \varphi+b}=\frac{1}{\sqrt{1-b^{2}}} \ln \left|\frac{(1-b) \operatorname{tg} 0.5 \varphi+\sqrt{1-b^{2}}}{(1-b) \operatorname{tg} 0.5 \varphi-\sqrt{1-b^{2}}}\right| & \text { for } b^{2}<1
\end{array}
$$

Using these indefinite integrals and taking into account the conditions of the ultimate limit state (6) - (7), one obtains the final formulae determining the normalized ultimate axial force $n_{R m}$ and the normalized ultimate bending moment $m_{R m}$ for the section under consideration:

$$
\begin{gathered}
-n_{R m}=\left(k_{2} /(k-2)\right)\left\{\begin{array}{c}
\left.\sin \alpha-\left(k_{1}+W_{2}\right) \alpha+2 W_{1} W_{2} /\left(\sqrt{b^{2}-1}\right) \operatorname{arctg}\left(\frac{(b-1) \operatorname{tg}(0.5 \alpha)}{\sqrt{b^{2}-1}}\right)\right\}+ \\
+\mu \frac{f_{y k}}{f_{c m}}\left\{\begin{array}{l}
-\alpha_{1}+\frac{\varepsilon_{\alpha}^{\prime}}{\varepsilon_{s s}}\left(\sin \alpha_{2}-\sin \alpha_{1}-\cos \alpha\left(\alpha_{2}-\alpha_{1}\right)\right) \\
{\left[\pi-\alpha_{2}+\varepsilon_{s s}\left(\pi-\alpha_{2}\right)\right]}
\end{array}\right\}
\end{array}\right. \\
m_{R m}=\left(k_{2} /(k-2)\right)\left\{\begin{array}{l}
0.5(0.5 \sin 2 \alpha+\alpha)+W_{1} W_{2} \alpha-k_{1} W_{2} \sin \alpha-2 W_{1} W_{2} b /\left(\sqrt{b^{2}-1}\right) \\
\operatorname{arctg}\left(\frac{(b-1) \operatorname{tg}(0.5 \alpha)}{\sqrt{b^{2}-1}}\right)
\end{array}\right\} \\
+\mu \frac{f_{y k}}{f_{c m}}\left\{\begin{array}{l}
\left.\left[-\sin \alpha_{1}+\varepsilon_{s s} \sin \alpha_{1}\right)\right]+ \\
\frac{\varepsilon_{\alpha}^{\prime}}{\varepsilon_{s s}}\left(0.5\left(\alpha_{2}-\alpha_{1}\right)+0.5\left(\sin 2 \alpha_{2}-\sin 2 \alpha_{1}-\cos \alpha\left(\sin \alpha_{2}-\sin \alpha_{1}\right)\right)+\right. \\
\left.\left[-\sin \alpha_{2}+\varepsilon_{s s} \sin \alpha_{2}\right)\right]
\end{array}\right\}
\end{gathered}
$$

where: 


$$
n_{R m}=N /\left(\pi d_{m} t f_{c m}\right), \quad m_{R m}=M /\left(\pi d_{m^{2}} t f_{c m}\right),
$$

$\mu$ - reinforcement ratio, $\alpha_{1}, \alpha_{2}$ - angles determining the depth of the plastified zones of steel in compression and in tension, respectively.

Using the above obtained formulae (15) - (17) the interaction curves with the normalized resistances $n_{R m}-m_{R m}$ have been plotted, when both the compressive and tensile strains occur in the analyzed section characterized by: the limiting value $\varepsilon_{c u}=-3.5 \%$, concrete grade $\mathrm{C} 20 / 25\left(f_{c m}=28 \mathrm{MPa}\right)$, yield stress of steel $f_{y k}=500 \mathrm{MPa}, E_{c m}=30 \mathrm{GPa}$, substitute reinforcement ratio $\mu f_{y k} / f_{c m}=0 ; 0.1,0 \leq \varepsilon_{s} \leq 10 \%$ (Fig. 2). Each curve denoted by the solid line (EC2) refers to the corresponding value of the substitute reinforcement ratio $\mu f_{y k} / f_{c m}$. The points on interaction curves correspond to the limiting compressive strain in concrete $\varepsilon_{c u}=-3.5 \%$ and tensile strain in steel $\varepsilon_{s}$. These curves are compared with those based on the parabola-rectangle diagram (the dashed line, parabola). It is apparent that the coordinates of curves denoted by EC2 are lower than for parabola.

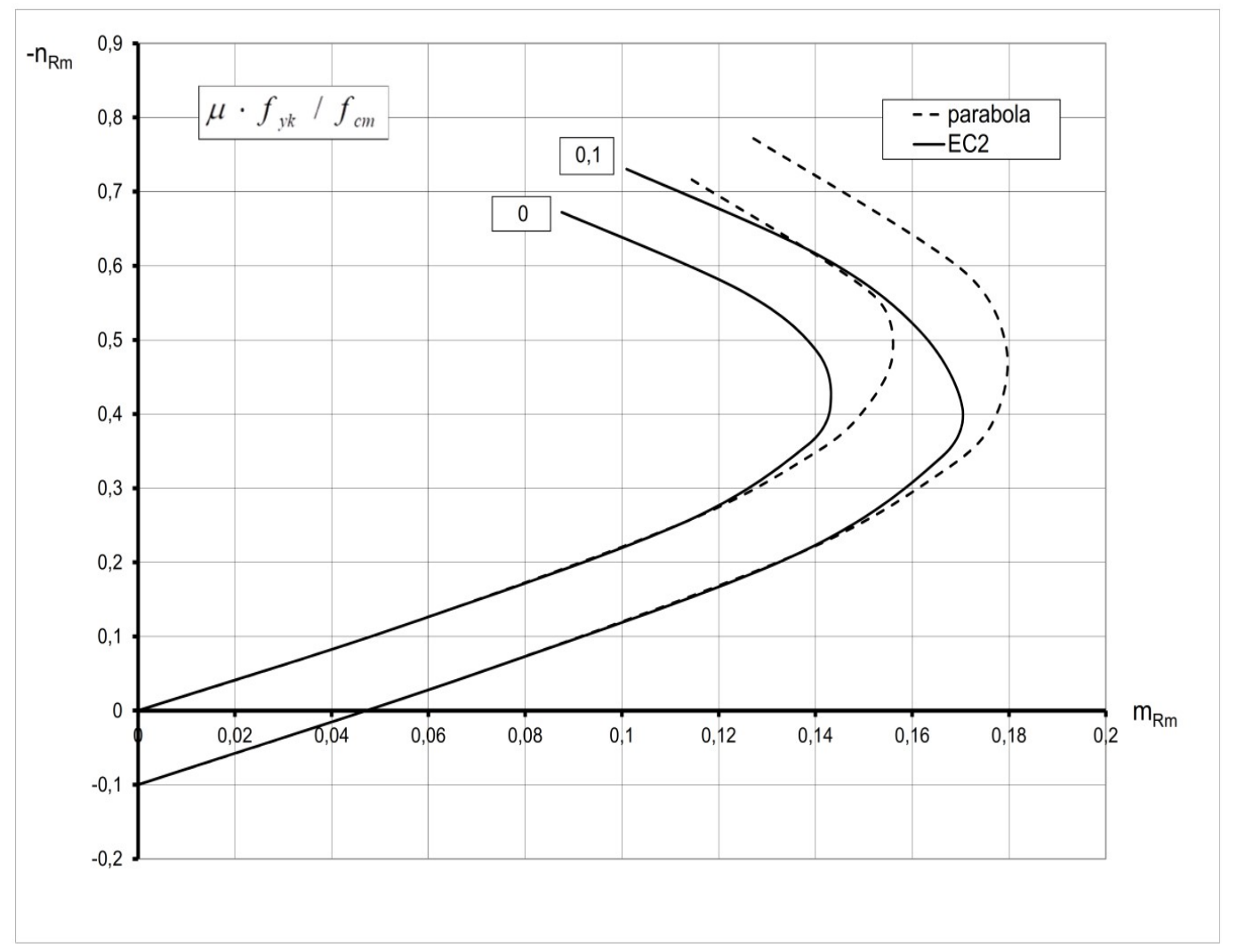

Figure 2. Interaction curves $n_{R m}-m_{R m}$ based on the nonlinear relation $\sigma_{c}-\varepsilon_{c}(\mathrm{EC} 2)$ versus those based on the parabola-rectangle diagram (parabola) for ring section subjected to bending with axial compressive force $(\varepsilon c u=-3.5 \%$ o $)$.

In a similar way one obtains the formulae for the ring cross-section wholly in compression. The geometrical relationship can be expressed in this case as:

$$
\varepsilon=0.5\left(\varepsilon_{2}-\varepsilon_{1}\right)(1-\cos \varphi)+\varepsilon_{1}
$$

where $\varepsilon_{1}, \varepsilon_{2}-$ the maximum and minimum compressive strains in the cross-section, respectively.

The formulae determining the cross-sectional forces $n_{R m}$ and $m_{R m}$ are described in the form: 


$$
\begin{gathered}
-n_{R m}=\left(k_{2} /(k-2)\right) \pi\left\{-\left(k_{1}+W_{2}\right)+W_{1} W_{2} /\left(\sqrt{b^{2}-1}\right)\right\}+ \\
\left(\mu f_{y k} / f_{c m}\right)\left\{-\alpha_{1}+1 / \varepsilon_{s s}\left[\left(k_{1}+k_{2}\right)\left(\alpha_{2}-\alpha_{1}\right)+k_{2}\left(\sin \alpha_{1}-\sin \alpha_{2}\right)+\pi-\alpha_{2}\right]\right\} \\
m_{R m}=-\left(k_{2}(k-2)\right) \pi\left\{0.5+W_{1} W_{2}-2 W_{1} W_{2} b /\left(\sqrt{b^{2}-1}\right)\right\}+ \\
\left(\mu f_{y k} / f_{c m}\right)\left\{-\sin \alpha_{1}+1 / \varepsilon_{s s}\left[\left(k_{1}+k_{2}\right)\left(\sin \alpha_{2}-\sin \alpha_{1}\right)-0.5\left(\alpha_{2}-\alpha_{1}+\sin 2 \alpha_{2}-\sin 2 \alpha_{1}\right)-\sin \alpha_{2}\right]\right\}
\end{gathered}
$$

where: $\quad k_{1}=2 \varepsilon_{1} /\left(\varepsilon_{2}-\varepsilon_{1}\right)+1, k_{2}=-0,5\left(\varepsilon_{2}-\varepsilon_{1}\right) / \varepsilon_{c 1}$ shall be substituted.

For the section wholly in compression, when $\left|\varepsilon_{c u}\right|>\left|\varepsilon_{c 1}\right|$, the formulae (19) - (20) describe the ring cross-section under consideration at the stage of concrete instability (at failure). It means that Drucker's stability postulates may not be satisfied [16, 17]. Therefore, the obtained curves can not be regarded in general as the carrying capacity curves. Such a case is presented in [7]. Fig. 3 presents interaction curves (EC2) resulting from the relation (1) versus those obtained on the basis of parabola-rectangle (parabola), extended to ring cross-section wholly in compression $\left(\varepsilon_{c 1}=-2.0 \%, \varepsilon_{c u}=-3.5 \%\right.$ o) with limitation to the values $m_{R m} \geq 0$. It indicates that the solutions based on the parabola-rectangle stress distribution in concrete may overestimate the section resistance. It is also apparent that the section resistance is strongly influenced by the concrete softening interpreted as the descending part of the $\sigma_{c}-\varepsilon_{c}$ curve. All curves in Fig. 2 and Fig. 3 satisfy the condition of convexity according to Drucker's postulate. In partucular, for $\varepsilon_{c u}=\varepsilon_{c 1}=-2 \%$ o the stability condition by Drucker is fulfilled for any values of $\varepsilon_{c}, \varepsilon_{s}$ and the obtained curves based on formulae (15) - (17), (19) - (20) can be regarded as the carrying capacity curves in the meaning accepted in the design codes. It is worth noting that these interaction curves (EC2) are very close to those based on the parabola-rectangle (parabola) (Fig. 4).

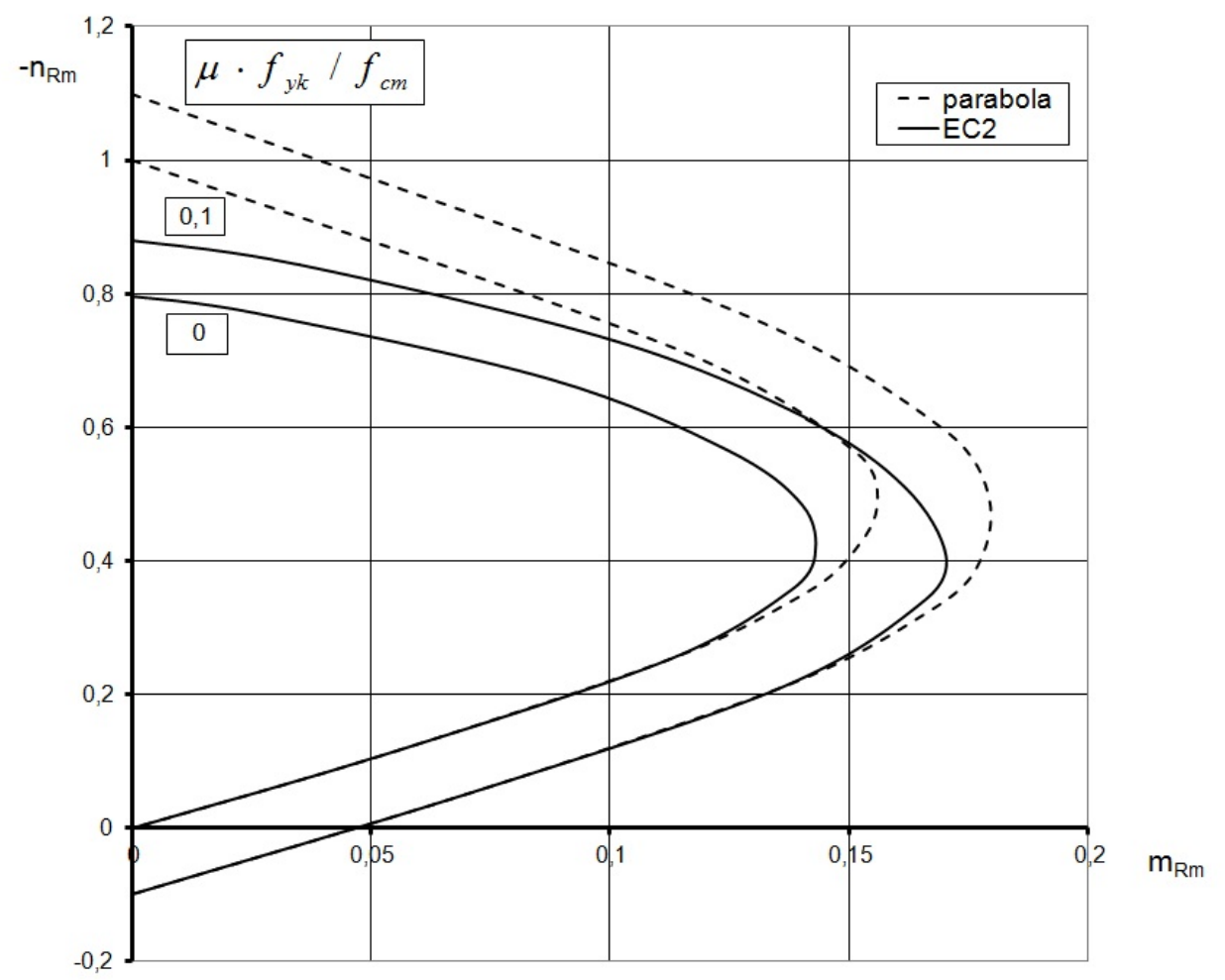

Figure 3. Interaction curves $n_{R m}-m_{R m}$ based on the nonlinear relation $\sigma_{c}-\varepsilon_{c}(\mathrm{EC} 2)$ versus those based on the parabola-rectangle diagram for concrete (parabola) extended for ring cross-section wholly in compression $\left(\varepsilon c u=-3.5 \%\right.$; $\left.m_{R m} \geq 0\right)$. 


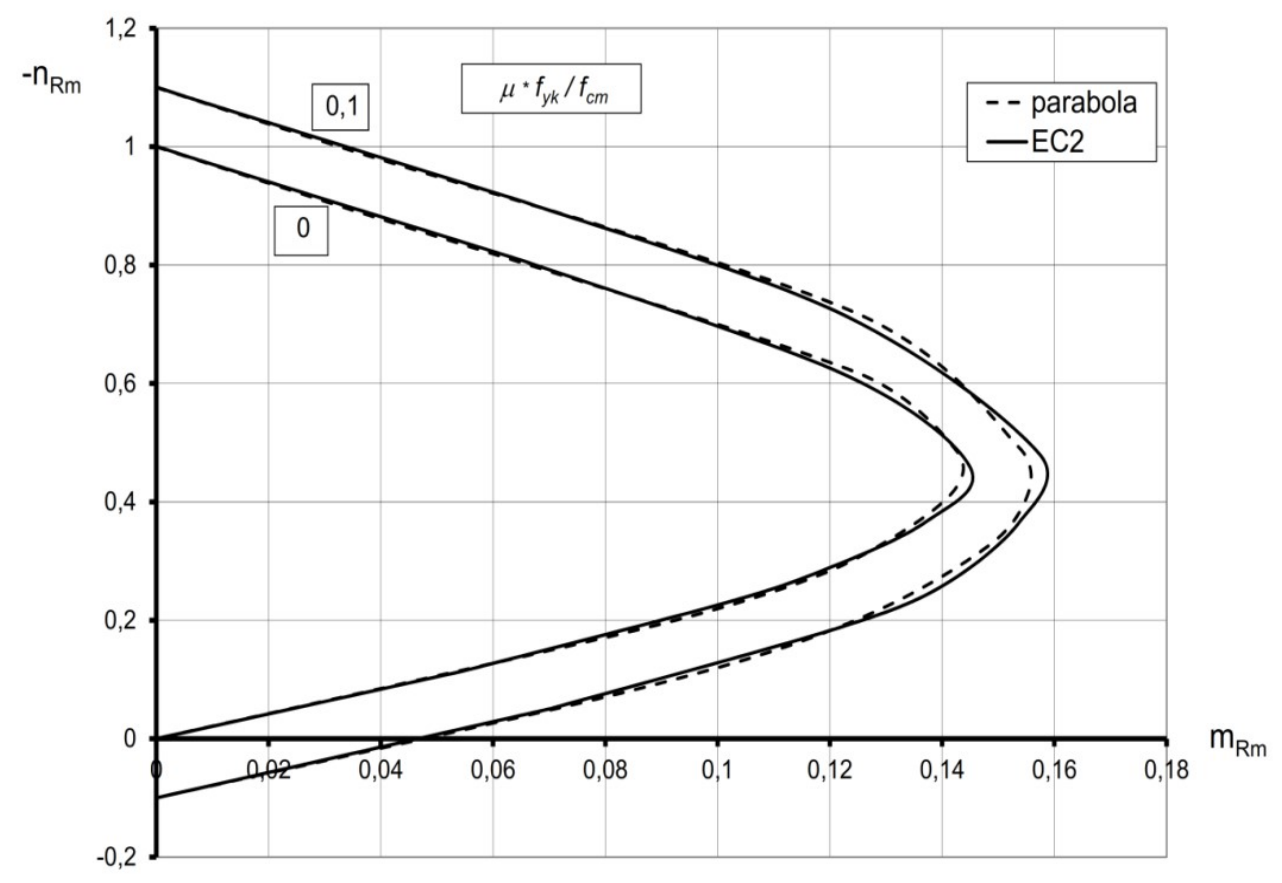

Figure 4. Comparison of the solution based on the nonlinear relation $\sigma_{c}-\varepsilon_{c}(\mathrm{EC} 2)$ with that based on the parabola-rectangle diagram for ring cross-section (parabola) and limiting value $\varepsilon_{c u}=\varepsilon_{c 1}=-2 \%$.

\subsection{Experimental verification with discussion of the results}

To verify the obtained analytical formulae, the tests on four RC designed columns with ring cross-section, denoted by Typ 2, were conducted in the Building Research Institute [13]. The outer diameter of all columns was $\mathrm{D}=0.6 \mathrm{~m}$ and the height $\mathrm{h}=2.0 \mathrm{~m}$. The inner diameter of columns was $\mathrm{d}=0.4 \mathrm{~m}$. On the basis of testing the mean compressive strength of the column concrete was determined as $f_{c m}=20 \mathrm{MPa}$. The reinforcement of the columns consisted of the longitudinal bars $\varnothing 16 \mathrm{~mm}$ made of steel B500C $\left(f_{y k}=500 \mathrm{MPa}\right)$. The corresponding reinforcement ratio was $\mu=1.024 \%$. To eliminate the risk of failure caused by the local stress concentration at the supports, the columns were strengthened in the both support zones by CFRP fabrics at the length of $0.5 \mathrm{~m}$. The investigations were conducted using the testing machine equipped with the top and bottom hinges. The tested specimens and experimental setup are presented in Fig. 5. The scope of the investigations covered determining the failure loads and strains of the columns. To apply loads four eccentricities were assumed: $e_{1}=11 \mathrm{~cm}, e_{2}=12 \mathrm{~cm}, e_{3}=12 \mathrm{~cm}, e_{4}=11 \mathrm{~cm}$. In each load step the strains of the concrete and reinforcing steel were measured in the middle section using strain gauges located along its circumference. The failure loads were determined as: $N_{1}=2490 \mathrm{kN}, N_{2}=2110 \mathrm{kN}$, $N_{3}=2200 \mathrm{kN}, N_{4}=2535 \mathrm{kN}$. The corresponding ultimate compressive strains in the concrete were measured as: $\varepsilon_{c u}=2.6 \%$ o, $\varepsilon_{c u}=2.5 \%, \varepsilon_{c u}=2.5 \%, \varepsilon_{c u}=3.4 \%$, the mean value $\varepsilon_{c u}=2.8 \%$. The failure mechanisms of the columns under consideration occurred in the form of crushing the concrete and yielding the longitudinal reinforcing steel in the middle part of the specimen (Fig. 5). All tested members underwent the same form of failure. The above described test results have been compared with the cross-section model presented in subsection 2.1. On the basis of the test results the following values were assumed in the calculations: the mean compressive strength of concrete $f_{c m}=20 \mathrm{MPa}$, the secant modulus of elasticity of concrete $E_{c m}=27 \mathrm{GPa}, \varepsilon_{c 1}=-1.8 \%$, the mean ultimate compressive strain for concrete: $\varepsilon_{c u}=-2.8 \%$, the substitute reinforcement ratio: $\mu f_{y k} / f_{c m}=0.2688$. Assuming these values, the interaction curve $n_{R m}-m_{R m}$ has been plotted using the derived formulae (15) - (20). The effect of confinement of the column (stirrups) was not analyzed. The comparisons presented in Fig. 6 show good conformity between the analytical solution represented by 
the interaction curve and the values of failure loads. As it is seen, the theoretical values are close to those obtained by column testing. The occurring differences between the analytical and experimental results are caused by measurement uncertainty (strains, eccentricity) as well as by ignoring the transverse reinforcement (stirrups) in the section model.
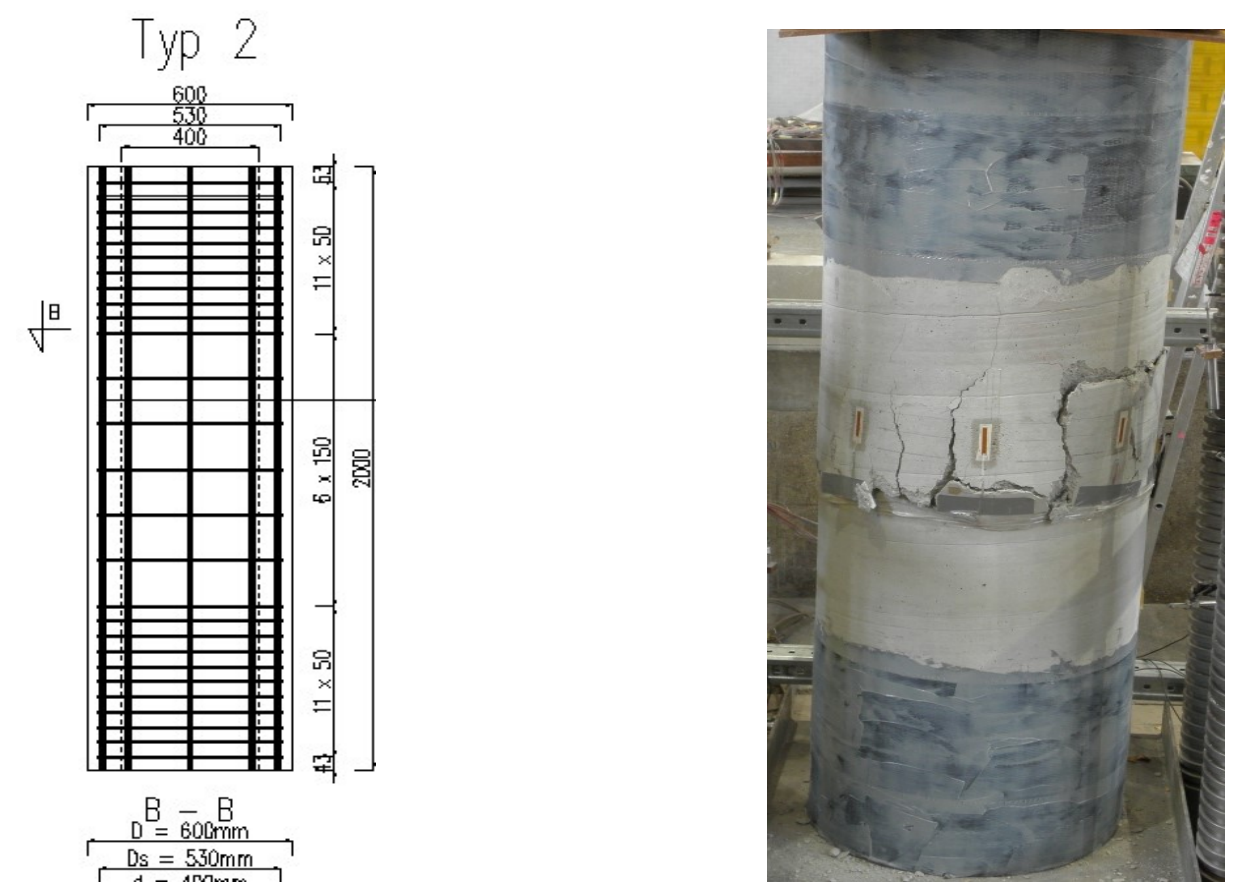

Figure 5. The specimen and the failure mode of column under eccentric compression.

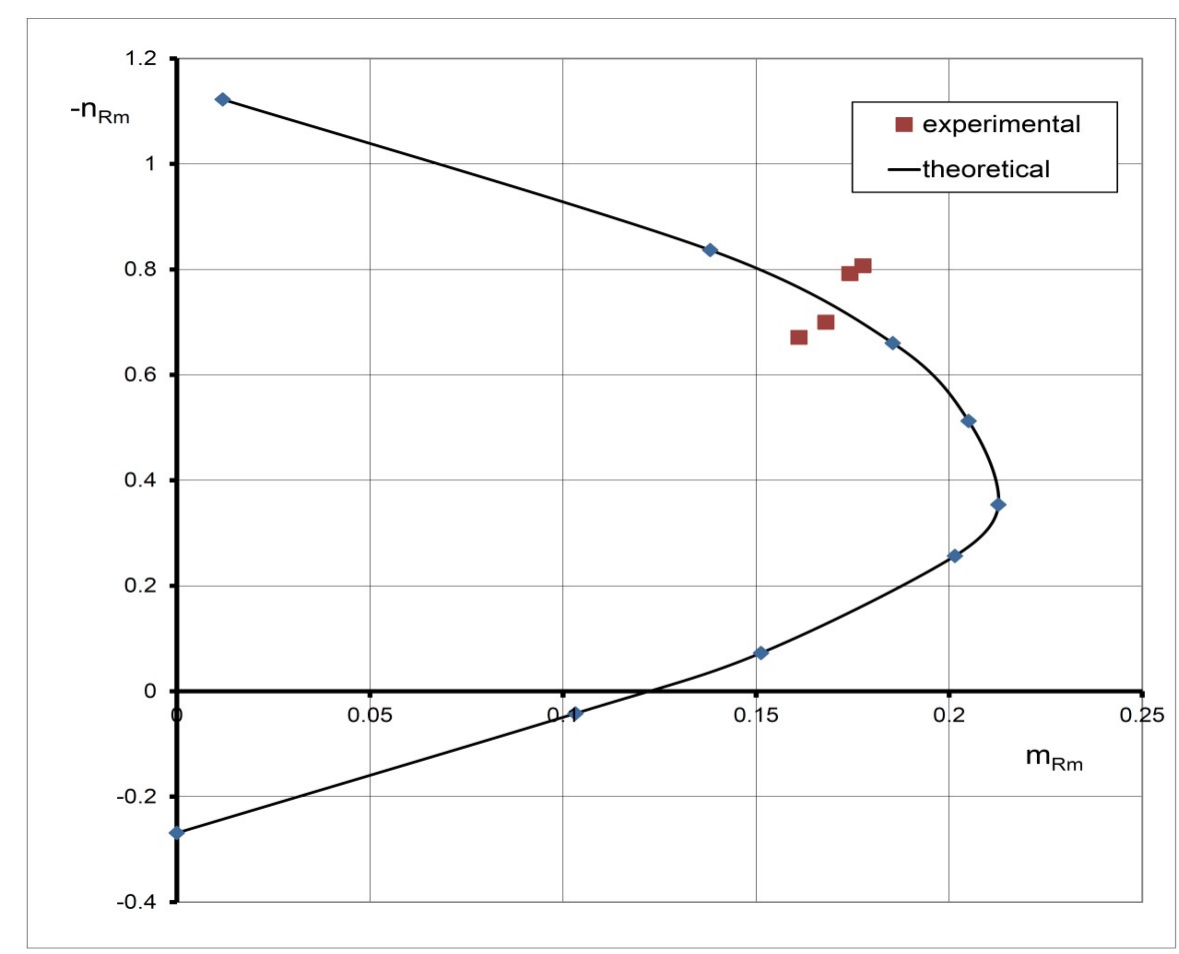

Figure 6. Comparison of the theoretical and experimental results for the tested columns.

In a similar way one obtains the corresponding interaction diagrams for rectangular cross-section. 


\section{Rectangular cross-section subjected to bending without axial force}

\subsection{Derivation of the ultimate bending moment}

The rectangular RC cross-section is subjected to the bending moment $M$ without axial force (Fig. 7).
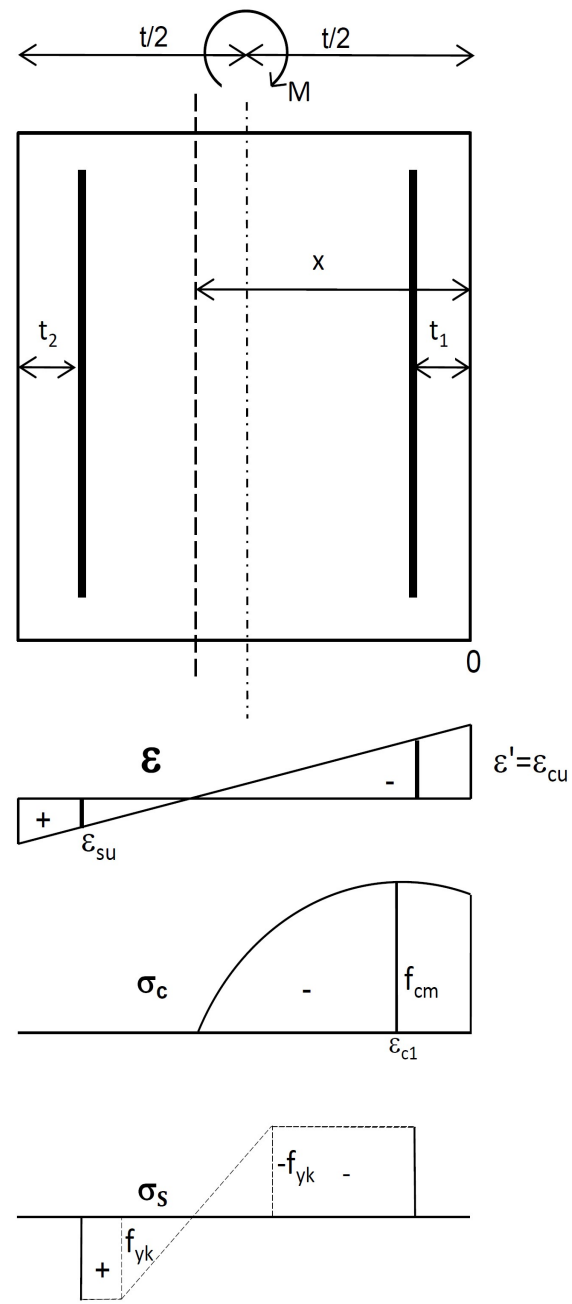

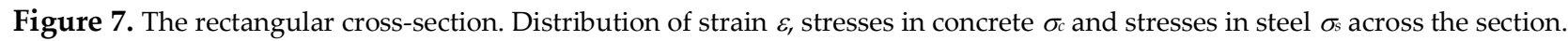

The assumption that plane sections remain plane is described as

$$
\varepsilon=\left(1-\frac{\xi^{\prime}}{\xi}\right) \varepsilon^{\prime}
$$

where: $\xi^{\prime}=x^{\prime} / t, \xi=x / t$ - dimensionless coordinate of any point of the rectangle and dimensionless coordinate describing the location of neutral axis, $\varepsilon^{\prime}$ - maximum compressive strain in concrete.

The equilibrium equation of the bending moments about the horizontal axis of the RC rectangle takes the following form:

$$
\int_{0}^{x} \sigma_{c}\left(0.5 t-x^{\prime}\right) d A_{c}+\sigma_{s 1} F_{a 1}\left(0.5 t-t_{1}\right)+\sigma_{s 2} F_{a 2}\left(0.5 t-t_{2}\right)-M=0
$$


where: $t$ - height, $b$ - width of the RC rectangle, respectively, $F_{a 1}, F_{a 2}$ - areas of reinforcing steels in compression and in tension, respectively, $t_{1}, t_{2}$ - coordinates describing the locations of compressive and tensile rebars, respectively, $\sigma_{s 1}$, $\sigma_{s 2}-$ stresses in steels in compression and in tension, respectively. As a result of integrating the equation (22), the normalized ultimate bending moment $m_{R m}$ is determined in the form:

$$
\begin{aligned}
& m_{R m}=(1 /(k-2))\left\{\begin{array}{l}
0.5\left(W_{1}+(1 /(k-2))\right) \xi+0.5\left[-W_{1}+0.5 k_{2}-((1 /(k-2))] \xi^{2}+\right. \\
-(1 / 3) k_{2} \xi^{3}-\left(W_{2} /\left((k-2) W_{3}\right)\right)\left[0.5 \ln W+\xi-\left(W / W_{3}\right) \ln W\right]
\end{array}\right\} \\
& +\mu_{1} \frac{f_{y k}}{f_{c m}}\left(0.5-\xi_{1}\right)\left\{-\delta_{k 1}+\delta_{k 1+1} \frac{\varepsilon^{\prime}}{\varepsilon_{s s}}\left(1-\frac{\xi_{1}}{\xi}\right)\right\}+\mu_{2} \frac{f_{y k}}{f_{c m}}\left(0.5-\xi_{2}\right)\left\{\delta_{k 2}+\delta_{k 2+1} \frac{\varepsilon^{\prime}}{\varepsilon_{s s}}\left(1-\frac{1-\xi_{2}}{\xi}\right)\right\}
\end{aligned}
$$

where: $\mu_{1}, \mu_{2}$ - reinforcement ratios of steels in compression and in tension,

$$
\begin{gathered}
m_{R m}=\frac{M_{R m}}{b t^{2} f_{c m}} \\
\xi=\frac{\left(1-\xi_{1}\right) \varepsilon_{c u 1}}{-\varepsilon_{s u}+\varepsilon_{c u 1}} \quad \varepsilon^{\prime}=\varepsilon_{u c 1},-\left(\frac{1}{\xi}-1\right) \varepsilon^{\prime}=\varepsilon_{s u} \\
k_{2}=\varepsilon^{\prime} /\left(\varepsilon_{c 1} \xi\right), W_{1}=k-k_{2} \xi, W_{2}=k(k-2)+1, W_{3}=(k-2) k_{2}, W=1+(k-2) k_{2} \xi ; \delta k=0,5\left((-1)^{k}+1\right) .
\end{gathered}
$$

\subsection{The resistance of composite steel and concrete beams versus test results}

This section model can be applied to determining the resistance of composite steel and concrete beams, named $\mathrm{BH}$ beams, subjected to bending. The beams under consideration consist of reinforced (RC) rectangular core placed inside a reversed TT welded profile, as shown in Fig. 8.

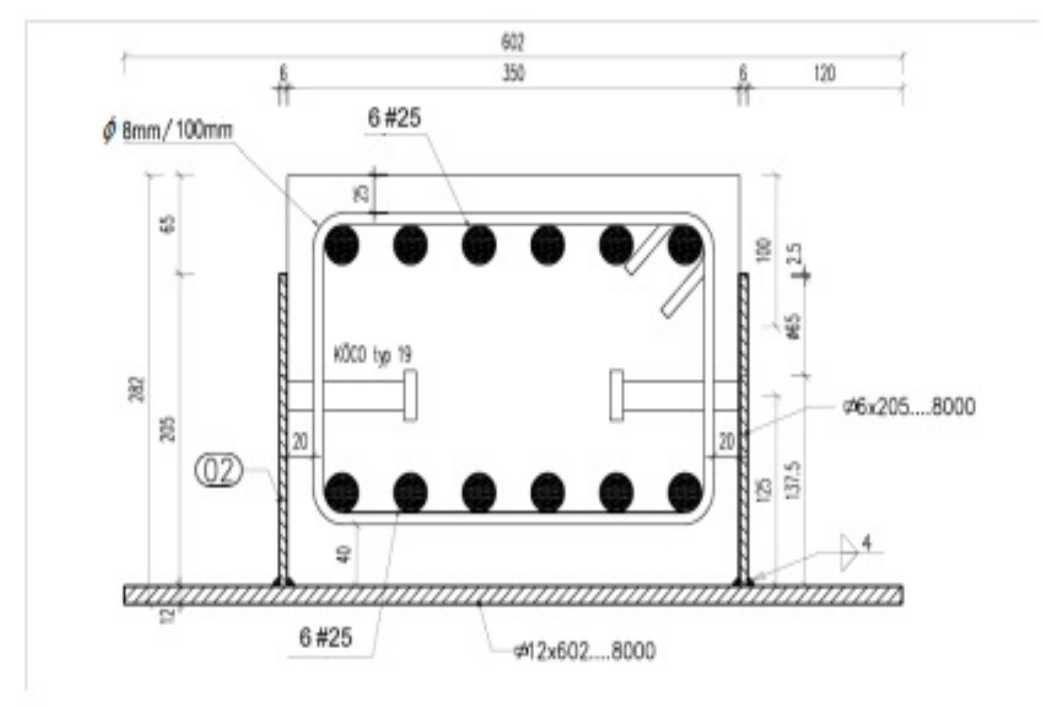

Figure 8. The cross-section of the composite beam under consideration.

The ultimate bending moment $M_{H R m}$ determining the resistance of the considered $\mathrm{BH}$ beam is derived in terms of strains by integrating the equilibrium equation of the bending moments about the horizontal axis of the RC core rectangle [18]. For verifying the obtained analytical solution the four-point bending tests were carried out in the Building Research Institute on three separated $\mathrm{BH}$ beams with the length of $L=7.88 \mathrm{~m}$. The beams were made of concrete with the mean compressive strength $f_{c m}=68 \mathrm{MPa}$ (concrete grade $\mathrm{C} 60 / 75 ; E_{c m}=39 \mathrm{GPa}$ ). For the RC rectangular core with the cross-section $0,27 \mathrm{~m} \times 0,35 \mathrm{~m}$, the reinforcing steel with yield stress $f_{y k}=500 \mathrm{MPa}$ was used, while for the profile steel with yield stress $f_{H y k}=460 \mathrm{MPa}$. The $\mathrm{BH}$ beams were loaded up to failure. The setup of the tests is presented in Fig. 9. The scope of the tests covered determining the failure loads and the corresponding strains. 
In each load step the strains in concrete $\varepsilon_{c}$, in reinforcing steels in compression $\varepsilon_{s 1}$ and in tension $\varepsilon_{s 2}$ as well as in the lower flange of profile steel $\varepsilon_{\mathrm{H} f}$ were measured using strain gauges located in the middle section of the $\mathrm{BH}$ beam.
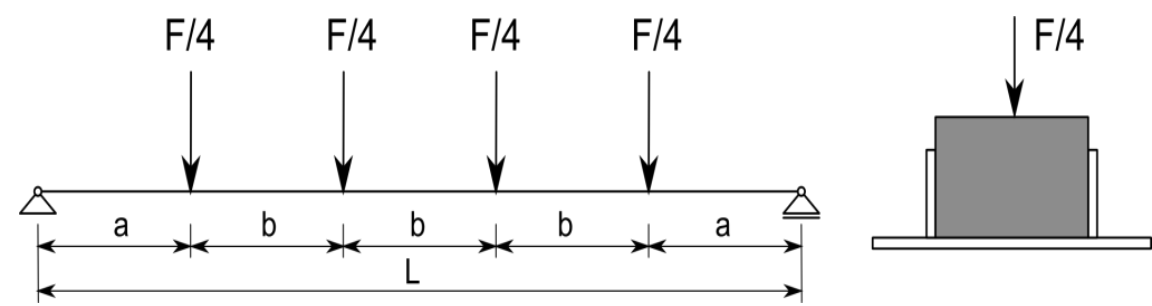

Figure 9. Setup of the bending tests; $L=7.88 \mathrm{~m}, \mathrm{a}=1.54, \mathrm{~b}=1.6 \mathrm{~m}$.

The failure mechanism of the $\mathrm{BH}$ beam occurred in the form of crushing the concrete (Fig. 10). In Table 1 the measured values of strains at failure, the bending moments at failure $M_{u}$ and resistances $M_{H R m}$ are collected. The compressive strains in concrete reached the ultimate values. The value $\varepsilon_{s l}=-2.89 \%$ indicates that plastic strains in the rebars in compression may have occurred. The values $M_{H R m}$ have been calculated according to the derived formulae (23) - (26). It is worth noting that they are close to the failure bending moments $M_{u}$ (relative differences $4.8 \%$ - $6.5 \%$ ). This shows very good agreements between the resistances $M_{H R m}$ and the test results in ultimate bending moments $M_{u}$.

Table 1. Bending test results of the $\mathrm{BH}$ beams.

\begin{tabular}{|c|c|c|c|c|c|}
\hline Concrete & $\begin{array}{l}\text { Reinforcing steel } \\
\text { in compression }\end{array}$ & $\begin{array}{l}\text { Reinforcing steel } \\
\text { in tension }\end{array}$ & $\begin{array}{c}\text { Profile } \\
\text { steel }\end{array}$ & $\begin{array}{l}\text { Failure } \\
\text { moment }\end{array}$ & Resistance \\
\hline $\begin{array}{l}\text { strain } \varepsilon_{c} \\
{[\% o]}\end{array}$ & $\begin{array}{l}\text { strain } \varepsilon_{s 1} \\
{[\% o \mathrm{o}]}\end{array}$ & $\begin{array}{l}\text { strain } \varepsilon_{s 2} \\
\quad[\% \text { o }]\end{array}$ & $\begin{array}{c}\text { strain } \\
\qquad H f \\
{[\% o]}\end{array}$ & $\begin{array}{c}M_{u} \\
{[\mathrm{kNm}]}\end{array}$ & $\begin{array}{l}\text { MHRm } \\
{[\mathrm{kNm}]}\end{array}$ \\
\hline-3.21 & -2.89 & 1.15 & 2.22 & 902.8 & 847.7 \\
\hline-3.04 & -2.13 & 1.13 & 2.25 & 883 & 842.4 \\
\hline-2.90 & -2.0 & 1.25 & 2.28 & 910.7 & 854.8 \\
\hline
\end{tabular}

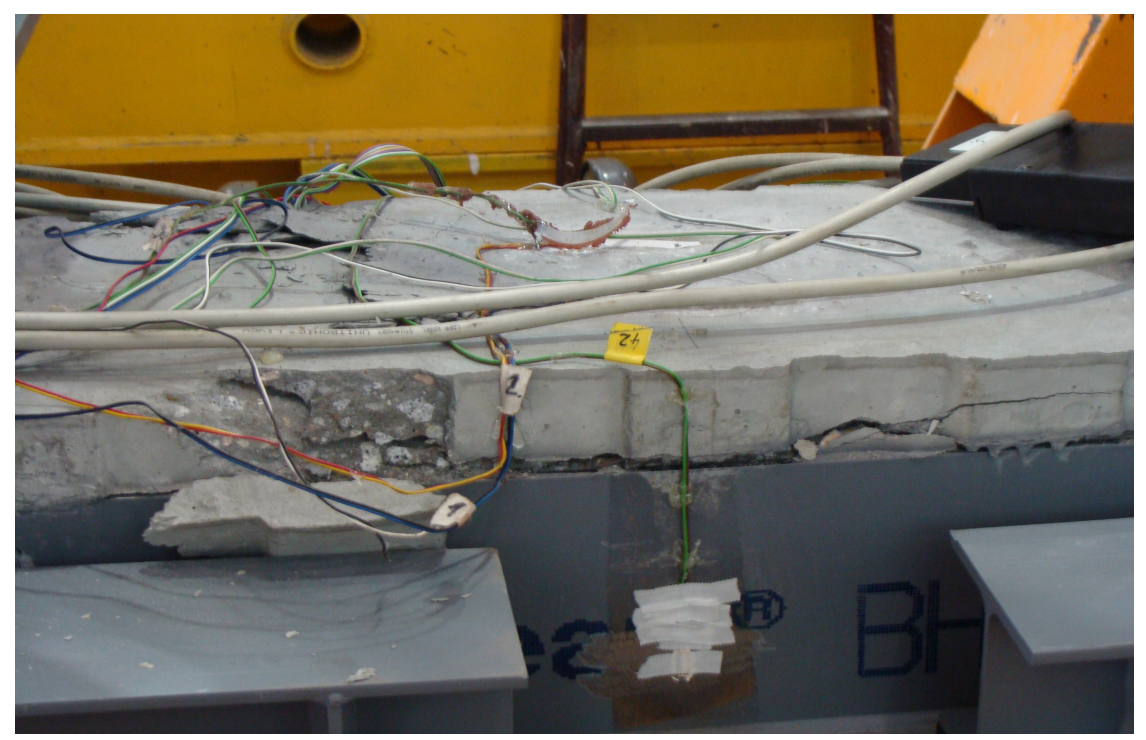

Figure 10. The characteristic failure mode of the $\mathrm{BH}$ beams.

\section{Conclusions}


The analytical formulae have been derived for analyzing the resistance of RC ring cross-section subjected to bending with axial force, based on the nonlinear stress-strain relationship for concrete that closely to reality represents the behavior of concrete in compression. In a similar way the corresponding formulae for other section shapes may be obtained. It was proved that calculated results conform to those obtained by testing on RC eccentrically compressed columns. The proposed approach results in more realistic evaluation of the resistance of the cross-section compared to that based on the parabolic-rectangular diagram for concrete in compression. Assuming the same nonlinear stress-strain relationship for concrete, the analytical solution was developed for the resistance of rectangular cross-sections subjected to bending without axial force. It served to derivation of the ultimate bending moment $M_{H R m}$ determining the resistance of the composite steel and concrete beams. The comparisons made between the computational and the test results showed good agreements in ultimate bending moments. The formulations like these enable to analyze the behavior of the cross-section of RC members and structures in the post-critical phase and in this respect they can be regarded as valuable solutions in the theory of reinforced concrete and concrete. In particular, they can be very useful as far as the prediction and verification of test results are concerned. The resistance of cross-sections is strongly influenced by the concrete softening represented by the descending part of the curve $\sigma_{c}-\varepsilon_{c}$ for concrete in compression. The developed section models can be easily implemented and effectively used in the structural design and maintenance of RC structures. Due to the positive verification by testing on the RC columns and $\mathrm{BH}$ beams, their suitability has been confirmed.

Author Contribution: Conceptualization; methodology; formal analysis; investigation; writing - original draft preparation; writing-review and editing; visualization. The author has read and agreed to the published version of the manuscript.

Funding: This research received no external funding.

Conflicts of Interest: The author declares no conflict of interest.

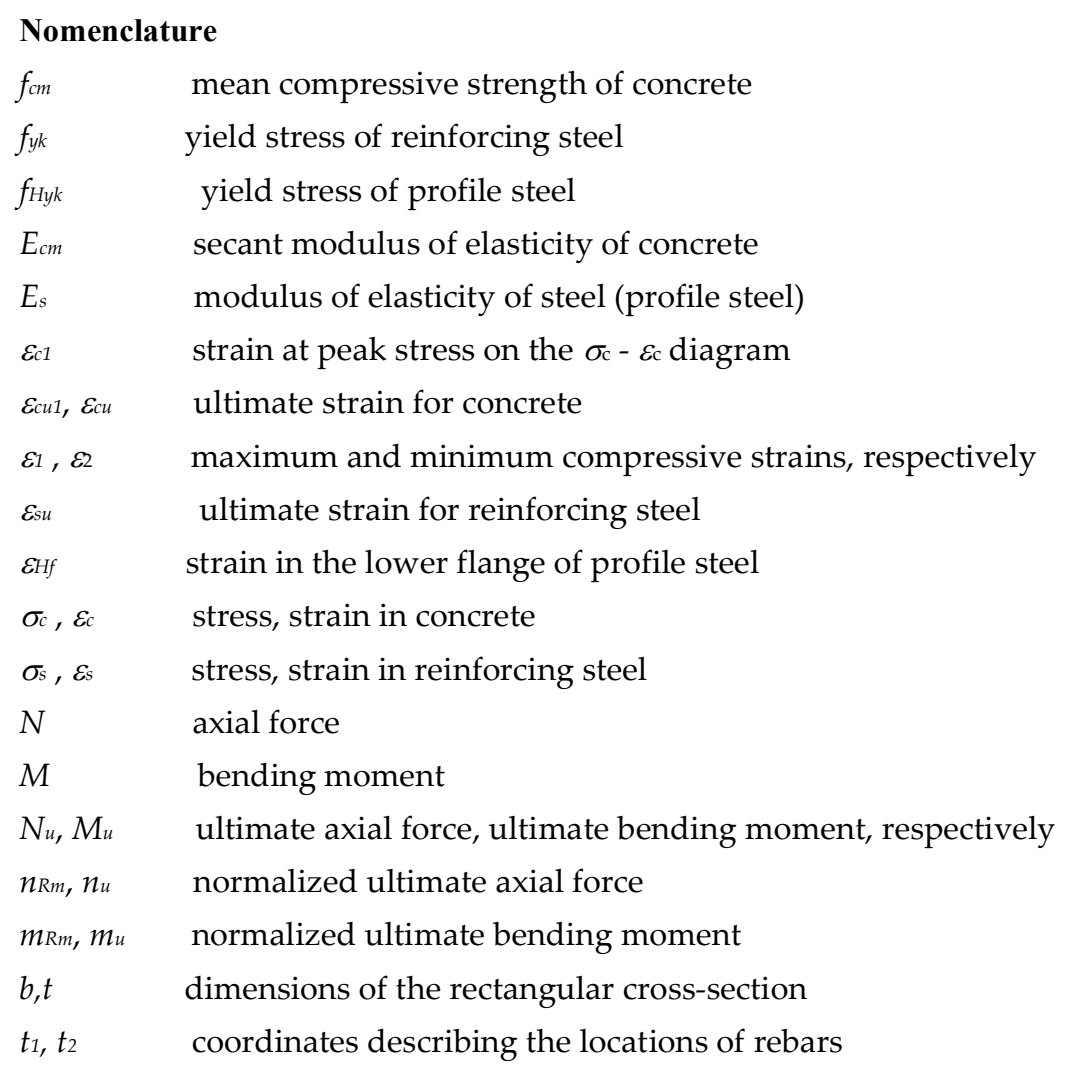


$x \quad$ coordinate describing the location of the neutral axis

$\sigma_{s 1} \quad$ compressive stress of steel

$\sigma_{s 2} \quad$ tensile stress of steel

$\mu_{1}, \mu_{2} \quad$ reinforcement ratios of steels in compression and in tension (rectangle)

$\mu \quad$ reinforcement ratio (ring)

$R \quad$ outer radius

$r \quad$ inner radius

$t=R-r \quad$ thickness of ring

$r_{m} \quad$ mean radius

$r_{s} \quad$ radius describing the locations of reinforcing steel on the reference circumference

$d_{m} \quad$ mean diameter

$\alpha \quad$ angle describing the location of the neutral axis, rad

$\varepsilon^{\prime} \quad$ maximum compressive strain in concrete, \%o

$\varphi \quad$ angular coordinate, rad

$d A_{s}, d A_{c} \quad$ element of the steel area $A_{s,}$ of the concrete area $A_{c}$, respectively.

\section{References}

1. Knauff, M.; Calculations of reinforced concrete structures according to EC 2 (in Polish), Scientific Publisher PWN: Warsaw, Poland, 2013.

2. Nieser H.; Engel, V. Structure of industrial chimneys, Commentary on DIN 1056, 1st ed.; Beuth Verlag GmbH, Berlin Köln, Germany, 1986.

3. Hognestad, E. Study of combined bending and axial load in reinforced concrete members, Bulletin No 399 1951, Engineering Experiment Station, University of Illinois, Urbana, pp. 128.

4. Popovics, S. A review of stress-strain relationships for concrete, ACI Journal 1970, vol. 67, issue 3, pp. $243-248$.

5. Popovics, S. A numerical approach to the complete stress-strain curve of concrete, Cement and Concrete Research 1973, vol. 3, issue, September, pp. 583-599.

6. Lechman, M. Resistance of RC annular cross-sections with openings subjected to axial force and bending, Eng. Trans. 2008, 56, 1, Polish Academy of Sciences, Institute of Fundamental Technological Research, pp. 43-64.

7. Lechman, M. Resistance of reinforced concrete columns subjected to axial force and bending, Transportation Research Procedia 2016, vol. 14C, pp. 2411-2420.

8. Lechman, M. A close to reality method for determining the resistance of RC structures under eccentric compression, Procedia Engineering 2017, 193, pp. 58-65.

9. Majewski, T.; Bobiński, J.; Tejchman, J. FE analysis of failure behavior of reinforced concrete columns under eccentric compression, Eng. Struct. 2008, 30, pp. 300-317.

10. Rodrigues, E.A.; Manzoli, O.L.; Bitencourt, L.A.G.,Jr.; dos Prazeres, P.G.C.; Bitencourt, T.N. Failure behavior modeling of slender reinforced concrete columns subjected to eccentric load, Lat. Amer. J. Solid. and Struct. 2015, Vol. 12, No. 3, pp. $520-541$.

11. Kim, J.K.; Lee, S.-S. The behavior of reinforced concrete columns subjected to axial force and biaxial bending, Eng. Struct. 2000, 23, pp. 1518-1528.

12. Lloyd, N.A.; Rangan, B.V. Studies on high-strength concrete columns under eccentric compression, ACI Struct. J. 1996, Vol. 93, Issue 6, pp. 631-638.

13. Chruściel, W. An advanced method for calculating the RC ring cross-section under eccentric compression, PhD Dissertation, Building Research Institute, Warsaw, Poland, 2013.

14. Lewiński, P.M.; Więch, P.P. Analytical model and numerical research of composite beams with horizontal studs, $8^{\text {th }}$ Int. Conf. "Analytical Models and New Concepts in Concrete and Masonry Structures" 2014, June 16-18, Wrocław, Poland.

15. Lewiński, P.M.; Derysz, J.; Dudziak, S.; Więch, P.P. Newly designed structural solutions for the "Slim floor" composite system, Proceedings of the fib Symposium 2019, Concrete - Innovations in Materials, Design and Structures, 27-29 May 
Kraków, Poland.

16. Drucker, D.C. A definition of a stable inelastic material, ASME J. Appl. Mech. 1959, 26, pp. 101-195.

17. Hill, R. General theory of uniqueness and stability in elastic-plastic solids, J. Mech. Phys. Solids 1958, 6, pp. $236-249$.

18. Lechman, M. Analytical solution for the resistance of composite beams subjected to bending, MATEC Web of Conferences 323, 01013, 2020.

19. „Model Code for Concrete Chimneys, Part A: The Shell”, Second Edition, Revision 1, CICIND, 2011.

20. ACI 307-08 "Code Requirements for Reinforced Concrete Chimneys and Commentary", American Concrete Institute, 2008.

21. EN 1992-1-1: 2010 Eurocode 2: Design of concrete structures - Part 1-1: General rules and rules for buildings.

22. EN 1994-1-1:2004 Eurocode 4: Design of composite steel and concrete structures: Part 1-1 General rules and rules for buildings. 